\title{
PRÁTICAS CONTÁBEIS E PROCESSO DECISORIAL: UMA ANÁLISE COM OS PRODUTORES RURAIS DO PARANÁ ${ }^{1}$
}

\section{ACCOUNTING PRACTICES AND DECISION-MAKING PROCESS: AN ANALYSIS WITH RURAL PRODUCERS IN PARANÁ}

\section{TÉCNICAS CONTABLES Y TOMA DE DECISIONES: UN ANÁLISIS CON LOS PRODUCTORES RURALES DEL PARANÁ}

\begin{abstract}
Mariana Viégas, Especialista em Contabilidade Financeira e Tributária pela Universidade Estadual de Londrina (UEL). Endereço: Universidade Estadual de Londrina (UEL), Rodovia Celso Garcia Cid - Pr 445 Km 380 - Campus Universitário - Cx. Postal 10.011 - Londrina PR - Brasil, CEP 86.057-970. Telefone: (43) 3371-4265. E-mail: viegasmariana@hotmail.com
\end{abstract}

Daniel Ramos Nogueira, Doutor em Controladoria e Contabilidade pela Faculdade de Economia e Administração da Universidade de São Paulo (FEA-USP). Endereço profissional: Universidade Estadual de Londrina (UEL) - Rodovia Celso Garcia Cid - Pr 445 Km 380 Campus Universitário, Londrina - PR, 86.057-970. Telefone: (43) 3371-4265. URL da Homepage: www.danielnogueira.com.br E-mail: danielnogueira@uel.br

\begin{abstract}
RESUMO:
O objetivo deste trabalho é verificar se os agricultores do município de Cambará-PR utilizam a contabilidade no processo decisorial em sua atividade. Para isso, foram aplicados questionários, caracterizando uma metodologia descritiva, por meio de um levantamento de dados. Pelos resultados apresentados pode-se concluir que a maior parte $(90 \%)$ dos agricultores se utiliza de algum controle ou anotação. Cerca de $70 \%$ dos respondentes, buscam sempre separar as despesas particulares e as da atividade. A maior parte dos controles são para atender as obrigações fiscais/contábeis. Daqueles que fazem anotações, apenas 30\% as utiliza para fins decisoriais. Estes resultados são convergentes com a literatura nacional e internacional sobre o assunto. Sugere-se que pesquisas futuras façam investigações sobre o processo de implantação das ferramentas decisoriais contábeis por períodos longos, analisando o impacto desta adoção. Palavras-chave: Contabilidade. Tomada de decisão. Controle de custos. Agronegócio.
\end{abstract}

\section{ABSTRACT:}

The objective of this work is to verify if the farmers of the municipality of Cambara-PR use the accounting in the decision-making process in their activity. For that, questionnaires were applied, characterizing a descriptive methodology, through a data survey. From the results presented, it can be concluded that most (90\%) farmers use some control or annotation. About $70 \%$ of the respondents always seek to separate the private expenses and those of the activity. The most part of the controls are to meet tax/accounting obligations. Those who take notes, only 30\% use them for decision-making purposes. These results are convergent with the national and international literature about the subject. It is suggested that future researches investigate in the long-term the process of implementing accounting decision-making tools,

1 Artigo submetido em 05/09/2017, revisado em 02/01/2019, aceito em 04/03/2019 e divulgado em 20/10/2019 pelo Editor Alexandre Rabêlo Neto, após double blind review.

GєCont, v.6, n. 1, Floriano-PI, Jan-Jun. 2019. 
analyzing the impact of this adoption.

Key words: Accounting. Decision making. Cost control. Agribusiness.

\section{RESUMEN:}

El objetivo de este trabajo es verificar si los agricultores del município de Cambará-PR utilizan la contabilidad en el proceso decisorio en su actividad. Para ello, se aplicaron cuestionarios, que caracterizaron una metodología descriptiva, por medio de una recopilación de datos. Por los resultados presentados, se puede concluir que, la mayor parte (90\%) de los agricultores utilizan algún control o apuntamiento. Alrededor del 70\% de los encuestados buscan siempre separar los gastos particulares de los de la actividad. La mayoría de los controles son para cumplir con las obligaciones fiscales/contables. De los que hacen anotaciones, sólo el 30\% las utiliza para fines decisorios. Estos resultados son convergentes con la literatura nacional e internacional sobre el tema. Se sugiere que investigaciones futuras hagan investigaciones sobre el proceso de implantación de las herramientas decisorias contables por períodos largos, analizando el impacto de esta adopción.

Palabras-clave: Contabilidad. Toma de decisión. Control de costos. Agronegócio.

\section{INTRODUÇÃO}

agronegócio possui papel importante na economia brasileira, gerando trabalho
e renda para as pessoas que se dedicam à atividades no meio rural (KRUGER;
MAZZIONI; BOETTCHER, 2009). Por isso, os agricultores buscam políticas que valorizem suas atividades, devido ao baixo valor pago pelas sacas produzidas e ao alto valor gasto com os insumos (HOFER et al., 2006).

Andrade et al. (2012, p. 25) relatam que "a dependência do agricultor em relação ao mercado, adicionada às incertezas e as mudanças significativas no cenário econômico, os produtores rurais devem ter conhecimento profundo de seu negócio, aprimorando-se na gestão e controle de suas atividades".

Buscando formas que diminuam seus custos de produção, que por vezes tende a ser até superior ao resultado final do produto, é de suma importância evitar desperdícios, planejandose antes de comprar os insumos. Assim, terá o montante do que realmente foi gasto, tendo uma informação precisa e tempestiva sobre a situação real da produção (HOFER et al., 2006).

Uma agricultura moderna com implementos agrícolas cada vez mais sofisticados e mercado consumidor mais exigente, faz com que os agricultores busquem formas de se modernizar quanto ao manejo das culturas cultivadas. Buscando um controle de custos e processo de gestão que acompanhe essa modernidade, fazendo com que o agricultor se mantenha competitivo no mercado, de forma a planejar seu negócio por meio de uma contabilidade rural que auxilie no controle, planejamento e apoio na tomada de decisão.

Segundo Brighenti et al. (2011, p. 12) "a contabilidade rural possibilita ao seu usuário organizar e planejar o desenvolvimento das atividades em seu estabelecimento, avaliando e reconhecendo as que geram maior lucratividade, visando a obtenção de melhores resultados futuros".

Desta forma, o agricultor consegue informações sobre a real situação de sua atividade. Por mais simples que seja, quando unida a contabilidade com uma boa gestão de custos se obterá informações úteis e relevantes da posição financeira daquela propriedade (BRAUM; MARTINI; BRAUN, 2013).

Mas será que os controles de custos e processos de gestão estão realmente presentes no cotidiano dos agricultores? Será que se utiliza de alguma ferramenta para processo de tomada de decisão? A partir destas questões provocativas que inspiraram esta pesquisa, o presente artigo visa responder a seguinte questão "Quais as práticas contábeis utilizadas pelos produtores 
rurais no processo decisorial?". Desta forma, este estudo objetiva verificar as práticas da contabilidade e o uso no processo decisório dos agricultores da cidade de Cambará-PR.

A presente pesquisa se justifica pois permitirá conhecer o ferramental decisorial utilizado pelos agricultores da região pesquisada. O agronegócio é uma área sujeita a intempéries e que sofre não só com as mudanças no clima, mas também, as alterações nos preços praticados no mercado. Ter um controle eficaz pode contribuir para a continuidade operacional destes produtores. Conhecer se eles detêm esse conhecimento é fundamental para que órgãos de classe possam oferecer treinamentos visando promover a melhor gestão do agronegócio. Estudos nacionais e internacionais demonstram que a utilização de controles contábeis é eficiente para o acompanhamento da evolução patrimonial de pequenos produtores, auxiliando na redução da pobreza e contribuindo para o crescimento financeiro (WALKER, 2014; SEVERO; TINOCO; OTT, 2017).

\section{REFERENCIAL TEÓRICO}

\subsection{CONTABILIDADE APLICADA AO AGRONEGÓCIO}

A contabilidade é um instrumento de apoio para os empresários, que segundo Crepaldi (2012, p. 39) "desempenha um importante papel como ferramenta gerencial, por meio de informações que permitam o planejamento, o controle e a tomada de decisão". Podendo assim avaliar o quão rentável é a atividade, lembrando que só atinge esta função se o empresário for honesto consigo mesmo, informando ali o que realmente foi gasto para desenvolvimento daquela atividade e as receitas que a mesma gerou, devendo também separar as suas despesas particulares, das depesas com sua atividade rural.

Por mais simples que seja, esta supervisão trará benefícios informando ao empresário o andamento de seu negócio, demonstrando se aquela atividade é lucrativa ou não, gerando informações para auxiliar na expansão dos negócios, redução de custos e/ou despesas, informando quando há necessidade de buscar novos recursos, financiamentos, investimentos, etc.

O agricultor deve aprender a calcular os reais custos de seu negócio de maneira que o mesmo gerencie custos e os utilize como estratégia, ampliando sua atividade e tendo um suporte na tomada de decisões (CREPALDI, 2008).

O produtor rural precisa saber onde estão sendo aplicados os recursos, para descobrir o seu retorno financeiro, devendo buscar um sistema de custeio que supra essas necessidades. $\mathrm{O}$ produtor é quem detém todas as informações econômico-financeiras de seu negócio, desta forma, precisa saber gerir estas informações para alcançar a eficácia, tendo assim o controle de cada atividade desenvolvida. Conforme menciona Crepaldi (2012, p. 73):

\footnotetext{
o produtor, antes de se decidir pela forma de cálculo e acompanhamentos dos custos, deve encarar seu negócio como uma opção de investimento que gere riqueza, isto é, planejar e controlar cada passo a ser dado, de forma que esqueça o "achismo" e tome suas decisões de forma equilibrada para que os erros estratégicos sejam minimizados ou até mesmo evitados.
}

Assim, surge a administração rural como descrito por Salume, Silva e Christo (2015, p. 77) "que orienta por meio de suas teorias e ferramentas a capacidade de gerir uma empresa agrícola visando maior dinamicidade para obter resultados favoráveis à condução da propriedade rural".

Quanto melhor for o gerenciamento da atividade rural mais resultados se obterá, tornando-se mais produtivos controlando os custos e maximizando o resultado. 
No Brasil a contabilidade rural ainda é pouco utilizada, tanto pelos empresários rurais quanto pelos contadores, isso se dá devido à mentalidade conservadora desses empresários, que não conseguem enxergar a real importância das informações geradas pela contabilidade, mantendo os seus controles baseados em experiências adquiridas ao longo dos anos (CREPALDI, 2012). Contudo, esta visão não é somente brasileira, pesquisas com produtores rurais na Espanha também demonstram que eles veem a contabilidade como útil principalmente para procedimentos fiscais (ARGILÉS; GARCIA-BLANDON; MONLLAU, 2011; BOSCH; ALIBERCH; GARCIA-BLANDÓN, 2012).

Nos dizeres de Kruger, Mazzioni e Boettcher (2009, p. 4) "a contabilidade pode ser aplicada buscando atender as necessidades de cada produtor rural e considerando as características das atividades que desenvolve, levando-se em consideração as particularidades de cada atividade".

Quanto mais conhecimento do que foi gasto no processo de produção melhor será desenvolvida a atividade, de forma que, proporcione suporte nas decisões a serem tomadas e ao que financeiramente precisa ser mais investido na atividade.

Como descrito por Callado e Callado (1998, p. 470):

é fundamental que o produtor rural esteja bem informado sobre a composição e o comportamento de seus custos para elaborar estratégias de ação fundamentadas em dados confiáveis, ponderadas e que busquem as melhores alternativas possíveis, além de possibilitar a visualização antecipada de restrições e dificuldades impostas pelas mudanças nos níveis de preço de mercado dos elementos componentes do custo rural.

Assim, torna-se fundamental que o produtor rural conheça profundamente sua atividade e as suas condições de mercado para tornar sua atividade mais lucrativa. A contabilidade rural tem a função de auxiliar no planejamento devido às informações que a mesma traz. Segundo Silva e Lopes (2008, p. 3):

desempenha um importante papel de ferramenta gerencial, que ajuda a diminuir os custos de produção, evitar desperdícios e melhorar o planejamento e controle de suas atividades, através de informações precisas e oportunas sobre a situação real da produção e do resultado das culturas de sua propriedade.

Atende a diversas atividades, se moldando as peculiaridades de cada uma. Conforme Kruger, Mazzioni e Boettcher (2009) se torna uma ferramenta indispensável, pela eficácia no auxílio ao contexto empresarial. Devendo o proprietário acompanhar sua contabilidade, trazendo a ela informações verídicas quanto à realidade de sua atividade rural.

\subsection{CONTROLES DE CUSTOS}

Segundo Leone e Leone (2010, p. 5) "a contabilidade de custos é o ramo da Contabilidade que se destina a produzir informações para os diversos níveis gerenciais de uma entidade". Para Martins (2003, p. 21) "a Contabilidade de Custos tem duas funções relevantes: o auxílio ao Controle e a ajuda às tomadas de decisões". Está dentro da contabilidade ao modo que auxilie na determinação dos custos de uma atividade, devendo estar integrada e se adaptando as necessidades de cada atividade a fim de atender necessidades gerenciais distintas, buscando os custos conforme sua relevância e variação no processo produtivo. Na atividade rural conforme Hofer et al. (2006, p. 32) "sua utilização contribui para melhorar o planejamento e controle dos custos". Já para Andrade et al. (2012, p. 27):

a Contabilidade de Custos e o sistema de controle de custos constituem ferramentas importantes para a administração e tomada de decisão em qualquer ramo de negócio, principalmente na agricultura, em razão de suas particularidades frente a qualquer 
outro empreendimento, seja em termos de seus custos e receitas, do fator tempo entre produção e venda e dependência do mercado.

Devendo o agricultor estar sempre bem informado dos custos de sua produção agrícola, para conseguir identificar o que realmente é gasto e necessário, utilizando segundo Callado e Callado (1998, p. 470), "esta informação como elemento auxiliar de sua administração para escolher as criações e as práticas agrícolas que deverão ser adotadas nos próximos períodos".

Desta forma, poderá se precaver com relação aos preços dos insumos agrícolas comparando-os com preços mais favoráveis, antes mesmo de iniciar sua produção, investindo somente o necessário para o desenvolvimento da atividade. A contabilidade de custos é de suma importância no meio rural, pois, demonstra para o empresário rural todos os seus gastos referentes à safra.

É a contabilidade que compara as despesas e custos orçados com os que realmente ocorreram, pois conforme caracteriza Santos, Marion e Segatti (2008, p. 41) "a Contabilidade de Custos está preocupada com a apuração do resultado, ou seja, identificar o lucro de forma mais adequada".

Tendo assim um controle dos custos que podem ser reduzidos ou até evitados. Segundo Hansen e Mowen (2001, p. 28) "a gestão de custos identifica, coleta, mensura, classifica e relata informações que são úteis aos gestores para o custeio (determinar quanto algo custa), planejamento, controle e tomadas de decisão". De certa forma que, ofereça suporte nas decisões a serem tomadas e ao conhecimento do que financeiramente precisa ser mais investido na atividade.

O papel do contador é de demonstrar ao agricultor a partir dos controles dos mesmos, qual o seu real custo de produção. Andrade et al. (2012, p. 27) destacam que "na agricultura, os custos são todos aqueles gastos relacionados direta ou indiretamente com a cultura (ou produto), tais como sementes, adubos, defensivos, combustíveis, mão-de-obra, etc.”.

Sobre a classificação dos custos, Silva e Lopes $(2008$, p. 3 ) relatam que "os custos que não variam de acordo com a produção e se mantém constante, independente da quantidade produzida, são os custos fixos, já os custos que tem seu valor afetado com o aumento ou diminuição da produção, são os custos variáveis", de forma a identificá-los para assim implantar estratégias para reduzi-los por meio de planejamento e planilhas de controle de custos.

\subsection{PESQUISAS RECENTES}

Kruger et al. (2014) visaram por meio de uma pesquisa exploratória, com questionários aplicados a pequenos produtores rurais do município de Erval Grande - RS, identificar as principais características do uso da contabilidade como instrumento de apoio no processo decisório, a qual teve como conclusão que pouco é usada a contabilidade no processo de gestão destas propriedades, há falta de controles e relatórios para decisões e a não separação das despesas particulares com as da atividade, evidenciando a necessidade da utilização da contabilidade no meio rural como instrumento de apoio ao processo de gestão dos custos, avaliação dos resultados para investimentos e embasamento das demais decisões.

Salume, Silva e Christo (2015) avaliaram através de uma pesquisa exploratória e descritiva a aplicação das premissas básicas e funções da administração rural e processo de gestão nas pequenas propriedades da cidade de Alegre - ES, concluindo que estas premissas não estão sendo usadas pela maioria, por mais que os produtores saibam da sua necessidade, no que diz respeito às funções da administração demonstram não ser executadas e planejadas corretamente, as quais quando bem exercidas podem contribuir para a gestão eficiente das pequenas propriedades rurais.

Kruger, Mazzioni e Boettcher (2009) procuraram demostrar as principais características das propriedades rurais do município de Águas de Chapecó - SC, visando a utilização da 
contabilidade rural e sua importância na gestão das propriedades rurais, como instrumento de apoio para a tomada de decisão, desenvolvendo assim uma pesquisa exploratória quantitativa, obtiveram como conclusão que grande parte dos entrevistados não separam as despesas pessoais com as da atividade, há uma carência de informações contábeis para tomadas de decisões, evidenciando que a contabilidade rural é uma ferramenta que pode melhorar o desempenho e a gestão das propriedades rurais.

Braum, Martini e Braun (2013) realizaram uma análise sobre as formas utilizadas pelos produtores rurais do município de Toledo - PR, para gerenciar os custos das atividades a fim de verificar se os conceitos da contabilidade de custos são aplicados na gestão da propriedade, por meio de uma pesquisa exploratória quantitativa, observou-se que a maioria dos entrevistados possuem conhecimentos dos custos e despesas de suas propriedades, fazendo a separação dos mesmos, por meio de anotações, planejando a cultura ou a atividade antes de desenvolvê-la.

Zanin et al. (2014) identificaram as características da estrutura e gestão das propriedades rurais do Oeste de Santa Catarina, por meio de uma pesquisa descritiva, com levantamento de dados em forma de questionários, verificando a necessidade dos agricultores buscar cursos de capacitação para executarem uma boa gestão, pois não utilizam a contabilidade como ferramenta no processo de gestão e decisório, revelando também a necessidade de uma estrutura para continuidade da atividade.

Ao investigar sobre o uso de controles de custos por produtores rurais familiares na cidade de Londrina-PR, Favato e Nogueira (2017) identificaram que os produtores tinham controles considerados básicos (anotações em cadernos) sobre o custo de produção, contudo, a tomada de decisão era baseada mais no conhecimento do produtor do que nas anotações e controles de custos.

\section{METODOLOGIA}

A pesquisa caracteriza-se como descritiva, que segundo Gil (2008, p. 28) "tem como objetivo primordial a descrição das características de determinada população ou fenômeno ou o estabelecimento de relações entre variáveis". Nesta pesquisa, buscando, portanto, verificar as práticas contábeis dos produtores rurais e o uso na tomada de decisão.

A coleta de dados ocorreu de modo transversal. O período se deu entre os meses de julho a agosto de 2016, no qual foram pesquisados 30 agricultores de forma não probabilística por acessibilidade do município de Cambará, situada na região norte do estado do Paraná, o qual, possui segundo informações da Prefeitura Municipal cerca de 1.549 agricultores cadastrados.

A coleta de dados ocorreu por meio de um questionário estruturado impresso composto por 19 questões, das quais a sua maioria eram questões fechadas, apresentando alternativas, que ofereciam ao respondente a liberdade em algumas questões de escolher mais de uma opção dentro de sua realidade, haviam também, questões abertas que ofereciam ao entrevistado o poder de expressar sua opinião ou descrever a forma como gerem suas propriedades e a importância de controles e contabilidade no auxílio da tomada de decisão e controle de gastos.

O questionário foi elaborado com base nos trabalhos de Kruger et al. (2014), Salume, Silva e Christo (2015), Braum, Martini e Braun (2013) e Kruger, Mazzioni e Boettcher (2009).

A análise dos dados foi realizada utilizando a estatística descritiva. Visando melhorar a compreensão dos dados foram elaboradas tabelas a partir dos dados coletados.

\section{APRESENTAÇÃO E INTERPRETAÇÃO DOS RESULTADOS}

GєCont, v.6, n. 1, Floriano-PI, Jan-Jun. 2019. 
Com a coleta dos dados buscou-se verificar como os agricultores do município de Cambará - PR utilizam a contabilidade no processo de controle de custos e tomada de decisão referente à sua atividade.

\subsection{DESCRIÇÃO DOS RESPONDENTES}

Primeiramente buscou-se conhecer o tamanho da área cultivada que cada agricultor entrevistado do município de Cambará possui (Tabela 1).

Tabela 1 - Tamanho da propriedade cultivada.

\begin{tabular}{lcc}
\hline \multicolumn{1}{c}{ Tamanho } & Quantidade & Percentual \\
\hline Entre 1 e 25 hectares & 7 & 23 \\
Entre 25 e 50 hectares & 5 & 17 \\
Entre 50 e 75 hectares & 3 & 10 \\
Acima de 75 hectares & 15 & 50 \\
Total & $\mathbf{3 0}$ & $\mathbf{1 0 0}$ \\
\hline
\end{tabular}

Fonte: Dados da pesquisa.

Conforme, a lei no 8.629 de 25 de fevereiro de 1.993 (BRASIL, 1993), em que apresenta como média propriedade aquela que possui de 1 a 4 módulos fiscais e grande propriedade aquela que apresenta área superior a 4 módulos fiscais até 15 módulos fiscais. Segundo informações do Instituto Ambiental do Paraná (IAP), um módulo fiscal no município de Cambará corresponde a 18 hectares. Sendo assim, 50\% dos entrevistados se enquadram como possuidores de grandes propriedades. Enquanto os outros $50 \%$ são possuidores de média propriedade.

Na Tabela 2 é demonstrada a atividade econômica desenvolvida por cada agricultor, as espécies cultivadas por eles durante as safras de verão e inverno, ou culturas permanentes as quais possuem tempo de produção superior a uma safra.

Tabela 2 - Atividades econômicas desenvolvidas no meio rural.

\begin{tabular}{|c|c|c|}
\hline Cultura & Quantidade & Percentual \\
\hline Soja & 30 & 36 \\
\hline Milho & 25 & 30 \\
\hline Trigo & 16 & 19 \\
\hline Cana-de-açúcar & 12 & 15 \\
\hline Total & 83 & 100 \\
\hline
\end{tabular}

Fonte: Dados da pesquisa.

Entre as respostas coletadas, a cultura da cana-de-açúcar representa $15 \%$ das escolhas, a cultura do trigo representa $19 \%$ e as culturas mais comuns entre os agricultores são a soja e o milho que juntos estão em $66 \%$ da cultura escolhida por cada agricultor.

É importante ressaltar que neste questionamento foram permitidos que escolhessem mais de uma cultura considerando que durante o ano têm-se as safras de verão e inverno, na qual nem sempre coincide o cultivo da mesma espécie. Nota-se que a soja é cultivada por todos os entrevistados. Também pode-se verificar que não houve nenhum agricultor que cultivasse apenas uma cultura, devido à instabilidade de preços estes procuram diversificar os riscos mesclando as escolhas, para assim terem produtos variados a oferecer ao mercado.

Após saber o que é mais cultivado pelos agricultores, solicitou que escolhessem entre as opções anteriormente apresentadas apenas aquela cultura considerada por eles como a mais lucrativa. Predominando a cultura da soja, escolhida por vinte dos trinta respondentes. 
Quando questionados se possuem sociedade com outros agricultores ou trabalham sozinhos, pode-se verificar que a maior parte 67\% (20 dos 30) trabalha em sociedades com outros agricultores, visto que são sociedades constituídas por irmãos, cerca de $33 \%$ trabalham individualmente em sua atividade. Para aqueles que possuem sociedade houve o seguinte questionamento: como era a divisão de tarefas administrativas? Entre as respostas dadas cerca de $65 \%$ disseram que todos da sociedade decidem juntos, quanto a qualquer assunto, cerca de $25 \%$ disseram que todos decidem, mas que um toma a frente para por em prática e $10 \%$ disseram que um toma conta da parte administrativa e o outro desenvolve a atividade da terra.

Tabela 3 - Faturamento bruto anual da propriedade

\begin{tabular}{lcc}
\hline \multicolumn{1}{c}{ Faturamento Bruto Anual } & Quantidade & Percentual \\
\hline Até $\mathrm{R} \$ 12.000,00$ & 0 & 0 \\
De $\mathrm{R} \$ 12.001,00$ até $\mathrm{R} \$ 24.000,00$ & 0 & 0 \\
$\mathrm{De} \mathrm{R} \$ 24.001,00$ até $\mathrm{R} \$ 48.000,00$ & 5 & 17 \\
De $\mathrm{R} \$ 48.001,00$ até $\mathrm{R} \$ 80.000,00$ & 5 & 17 \\
Acima de $\mathrm{R} \$ 80.000,00$ & 20 & 66 \\
Total & $\mathbf{3 0}$ & $\mathbf{1 0 0}$ \\
\hline
\end{tabular}

Fonte: Dados da pesquisa.

Os resultados da Tabela 3 demonstram que $66 \%$ dos entrevistados possuem um faturamento bruto anual acima de $\mathrm{R} \$ 80.000,00$ (oitenta mil reais). Dos que possuem faturamento bruto anual até $\mathrm{R} \$ 48.000,00$ (quarenta e oito mil reais) somam 17\%, resultado idêntico aos que faturam entre $\mathrm{R} \$ 48.001,00$ e $\mathrm{R} \$ 80.000,00$ (oitenta mil reais) por ano.

Sabendo-se o faturamento bruto anual buscou-se descobrir se o mesmo é suficiente para mantê-los desenvolvendo sua atividade agrícola, em sua maioria, disseram possuir o faturamento suficiente, com exceção de apenas um respondente alegando não possuir faturamento que seja suficiente para cobrir seus gastos e despesas necessárias para desenvolver a atividade.

\subsection{CONTROLE DE CUSTOS E PROCESSO DECISORIAL}

Procurou-se saber, se os agricultores conseguiam definir o total gasto durante a safra. Pode-se verificar que dos 30 entrevistados, 24 conseguem definir o que foi gasto durante a safra. Para estes questionou-se como conseguem fazer essa definição, as respostas foram diversas, sendo que alguns disseram por controle de notas de compras, por meio de anotações, outros por acompanhamento de todas as despesas, por controles em planilhas e pelo pacote/fechamento ofertado pela cooperativa.

$\mathrm{Na}$ Tabela 4, buscou-se saber se havia separação das despesas particulares dos agricultores com as da atividade agrícola, 50\% dos entrevistados disseram sempre separar as despesas. Algo correto do ponto de vista contábil, pois não devem confundir despesas particulares com as relacionadas à sua atividade. $20 \%$ disseram que na maioria dos casos separam as despesas particulares com as da atividade agrícola, $3 \%$ disseram que são poucos os casos de separação e $27 \%$ disseram não fazer nenhum tipo de separação de despesas.

Tabela 4 - Separação das despesas particulares com as da atividade.

\begin{tabular}{|c|c|c|}
\hline Fatores & Quantidade & Percentual \\
\hline Sim, sempre. & 15 & 50 \\
\hline Sim, na maioria dos casos. & 6 & 20 \\
\hline Às vezes. & 0 & 0 \\
\hline Não, são poucos os casos. & 1 & 3 \\
\hline
\end{tabular}

GєCont, v.6, n. 1, Floriano-PI, Jan-Jun. 2019. 
Não faço nenhum tipo de separação.

8

27

Total

30

100

Fonte: Dados da pesquisa.

Outro questionamento feito aos agricultores é se possuíam alguma anotação para controle de seus gastos. Dos quais 27 (90\%) dos entrevistados fazem anotações para tomarem alguma decisão e controlarem seus custos, um resultado bem satisfatório, pois demostra por mais simples que seja a maior parte dos entrevistados possui uma espécie de contabilidade, mas já é algo que lhes ajuda saber o quanto gastaram durante a safra. Para estes 27 produtores que detêm controles de custos questionou-se sobre a finalidade dessas anotações (Tabela 5).

Tabela 5 - Finalidade das anotações.

\begin{tabular}{lcc}
\hline \multicolumn{1}{c}{ Fatores } & Quantidade & Percentual \\
\hline Anotações e/ou registros a fim de realizar a contabilidade & 16 & 21 \\
Anotações/registros para fins de Imposto de Renda & 14 & 19 \\
Para servir de base para seguros, arrendamentos e outros contratos & 10 & 13 \\
Gerenciar as despesas pessoais do proprietário e de sua família & 8 & 11 \\
$\begin{array}{l}\text { Apoiar as tomadas de decisões no planejamento, nas vendas e dos } \\
\text { investimentos }\end{array}$ & 8 & 11 \\
Gerenciar as despesas e os custos das atividades (culturas, criação de & 7 & 9 \\
animais) & 5 & 8 \\
Auxiliar as projeções de fluxo de caixa e necessidade de crédito & 4 & 5 \\
Medir e avaliar o desempenho econômico-financeiro da empresa por & 2 & 3 \\
Fazividade & $\mathbf{7 4}$ & $\mathbf{1 0 0}$ \\
Total & & \\
\hline
\end{tabular}

Fonte: Dados da pesquisa.

Para a Tabela 5 foi permitido assinalar mais de uma resposta, aqueles que responderam que fazem anotações, $21 \%$ a utilizam para realizar a sua contabilidade, $19 \%$ disseram utilizálas para fins de imposto de renda e $13 \%$ disseram servir de bases para realizar seguros, arrendamentos, financiamentos e outros contratos, $11 \%$ a utilizam para gerenciar as despesas pessoais do proprietário e de sua família e outros $11 \%$ utilizam as anotações para apoiar as tomadas de decisões no planejamento, nas vendas e dos investimentos e $9 \%$ a utilizam para gerenciar despesas e custos da atividade. Como se pode verificar, os três itens com maior percentual de resposta referem-se a obrigações fiscais ou procedimentais, sendo que o uso para tomada de decisão e gerenciamento aparecem a partir da quarta colocação entre os itens mais assinalados. Destaca-se que 8 dos 27 respondentes (30\%) que fazem anotações utilizam-se das informações como apoio para a tomada de decisões.

A Tabela 6 evidencia a função da contabilidade para o agricultor, $40 \%$ veem a contabilidade como forma de calcular impostos e fazer declarações ao governo e $7 \%$ desconhece a finalidade da contabilidade, e para 53\% auxilia no processo de gestão e tomada de decisão dos mesmos, o que pode-se verificar é que os agricultores sabem o quanto importante a contabilidade, mas não a executam na prática, deixando para dar a devida atenção somente na época do imposto de renda.

Tabela 6 - Função da contabilidade para o agricultor.

\begin{tabular}{ccc}
\hline Tipos & Quantidade & Percentual \\
\hline Calcular impostos e fazer declarações ao governo & 12 & 40
\end{tabular}

GєCont, v.6, n. 1, Floriano-PI, Jan-Jun. 2019. 
Auxiliar no processo de gestão e tomada de decisão 16

Desconhece suas finalidades

Total

Fonte: Dados da pesquisa.

Quando questionados se possuem contabilidade rural em dia, apenas 20\% mantém sua contabilidade em dia, a grande maioria $43 \%$ só a faz na época do imposto de renda, mesmo sabendo que a contabilidade pode lhes auxiliar no processo de gestão de sua atividade. $37 \%$ não faz nenhum tipo de contabilidade, isso mostra o desinteresse por parte dos agricultores em ter uma contabilidade rural que lhes ajude na tomada de decisão, mesmo que muitos saibam de sua importância não a utilizam.

No Gráfico 1 questionou-se quanto ao planejamento financeiro no início de cada safra e caso ocorresse uma quebra de produtividade por fatores não controláveis ou imprevistos. A grande maioria $83 \%$ planeja-se antes de iniciar a safra, buscando fazer orçamentos para verificar o quanto será gasto para assim ter uma estimativa de investimento, enquanto $17 \%$ não fazem nenhum tipo de planejamento.

Confrontando este resultado com aqueles obtidos na Tabela 5 (onde poucos produtores informaram fazer anotações para 'projeções'), conclui-se que estes orçamentos devem ser feitos de forma reflexiva pelos produtores, não se utilizando de anotações ou procedimentos formais para a realização do orçamento.

Gráfico 1 - Planejamento no início da safra e para quebra de produtividade.

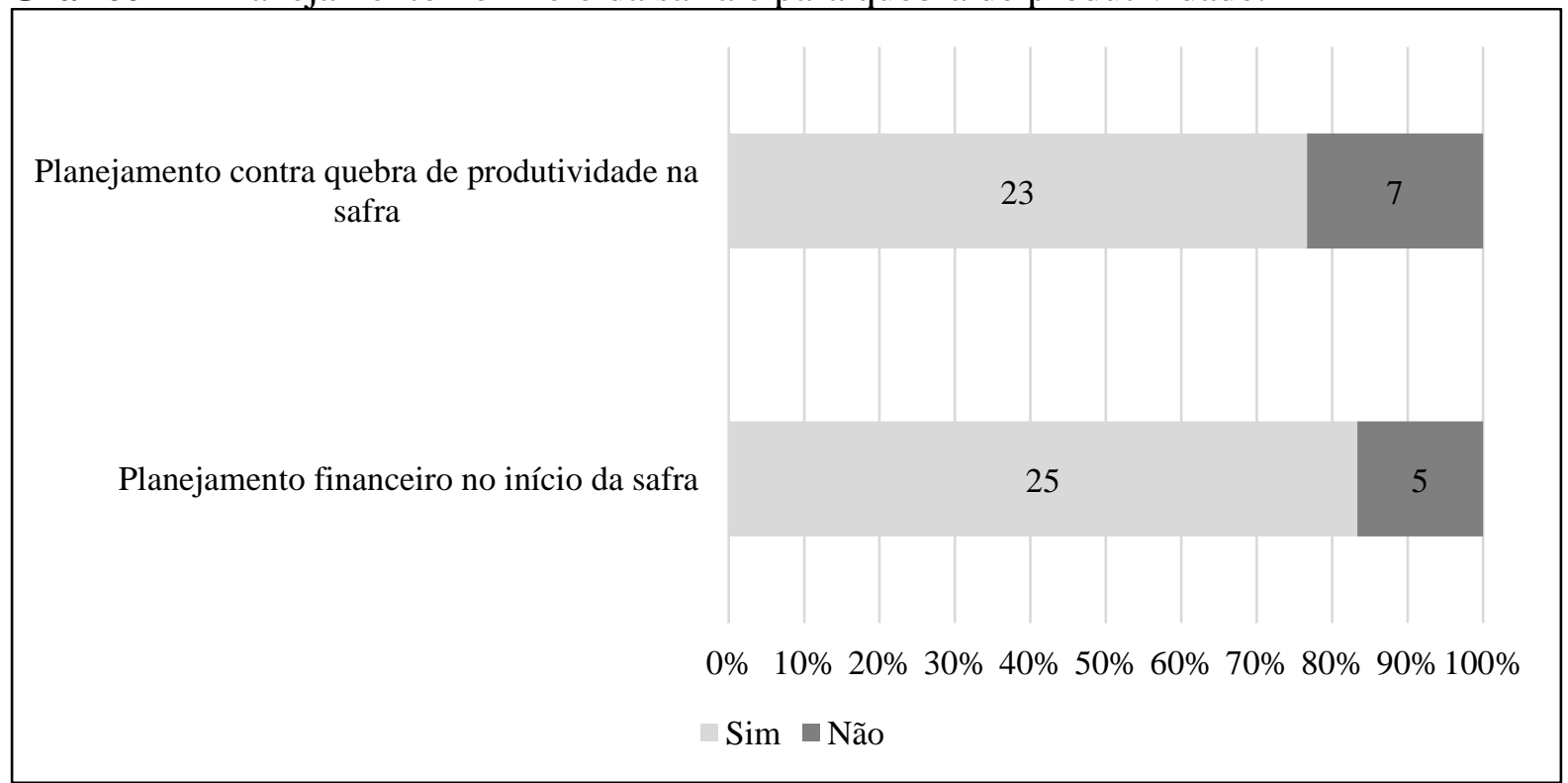

Fonte: Dados da Pesquisa.

Com relação a quebra na produtividade da safra, a qual pode ser ocasionada por fenômenos climáticos, 77\% disseram se precaver desses acontecimentos, os quais foram questionados como fazem essa prevenção, a grande maioria se utiliza de seguros agrícolas ou Proagro, há também aqueles que guardam os lucros que sobram das safras anteriores para assim terem subsídios caso ocorra um fenômeno climático que lhe cause prejuízo. 
Gráfico 2 - Reinvestimento dos Lucros.

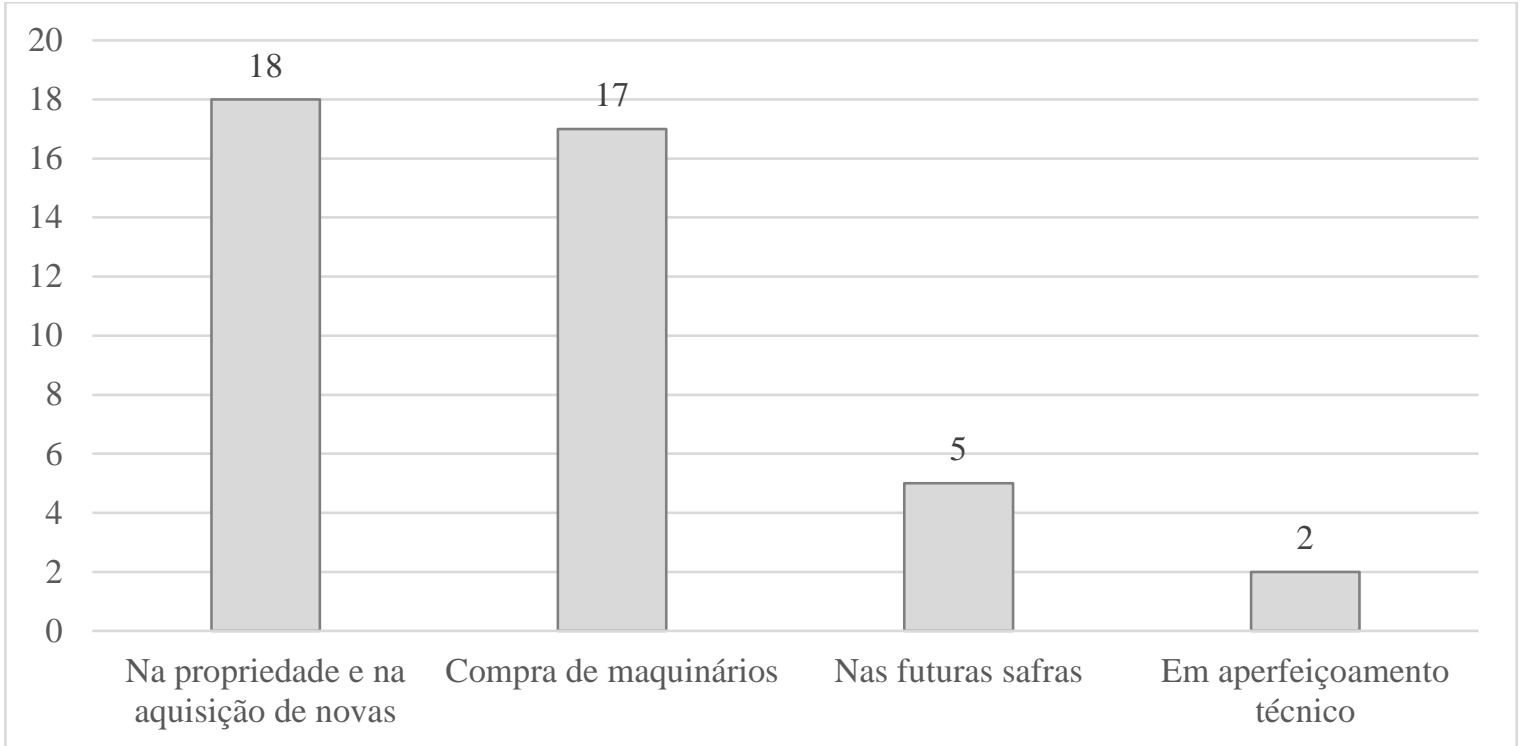

Fonte: Dados da Pesquisa.

Sobre o reinvestimento dos lucros (Gráfico 2), ressaltando que neste questionamento deu-se a liberdade de assinalar mais de uma alternativa, cerca de $43 \%$ (18) reinvestem na propriedade ou na aquisição de novas áreas, $40 \%$ (17) compram novos maquinários, $12 \%$ (5) poupam para safras futuras e apenas $5 \%$ (2) investem em aperfeiçoamento técnico.

\subsection{DISCUSSÃO DOS RESULTADOS}

Comparando a presente pesquisa com a apresentada nos trabalhos de Kruger et al. (2014), Salume, Silva e Christo (2015), Braum, Martini e Braun (2013) e Kruger, Mazzioni e Boettcher (2009) percebe-se que nesta a atividade desenvolvida pelos agricultores limita-se em apenas quatro (soja, milho, trigo e cana-de-açúçar, esta última não citada em nenhum dos trabalhos que deram embasamento para este), mostrando que no trabalho desses autores tiveram participantes com uma diversidade maior de atividades, tais como, pecuária, avicultura, suinocultura, etc, fato este explicado principalmente pela diferença regional entre as pesquisas, sendo que a cultura desenvolvida depende em grande parte do clima e aspectos geográficos da região.

De forma comparativa com os trabalhos de Kruger, Mazzioni e Boettcher (2009) e Kruger et al. (2014) obteve-se que, os seus participantes conseguem definir o gasto de sua produção, assim como os participantes desta pesquisa.

Nota-se que o resultado quanto a separação dos gastos particulares com os da atividade rural, apresentou diferença quando comparado ao de Kruger et al. (2014), uma vez que encontrou-se que apenas 30\% dos respondentes não separam as despesas, enquanto na pesquisa de Kruger et al. (2014) 61\% não faziam esta segregação. Se analisada a finalidade da contabilidade na percepção do respondente, o presente trabalho apresenta um resultado também diferente, pois apresenta um percentual menor (7\%) em relação ao entrevistado desconhecer a sua finalidade quando comparado aos resultados obtidos (48\%) por Kruger et al. (2014). Um dos fatores que pode ajudar a explicar essa diferença é que na pesquisa de Kruger et al. (2014) a maioria dos respondentes (80\%) tinha uma área cultivada de 1 a 15 hectares, enquanto nesta pesquisa, $77 \%$ dos respondentes tem acima de 25 hectares, apresentando assim indícios que propriedades maiores tendem a ter um maior controle contábil-financeiro e também regimes tributários que exigem maior controle contábil quando comparado às pequenas propriedades. 
Referente à finalidade das anotações predominaram a maior opção pelas alternativas: 1) Anotações e/ou registros a fim de realizar a contabilidade, 2) Anotações/registros para fins de Imposto de Renda e 3) Para servir de base para seguros, arrendamentos e outros contratos, enquanto no trabalho de Braum, Martini e Braun (2013) o que prevaleceu como opção foi: 1) Gerenciar as despesas e os custos das atividades (culturas, criação de animais), 2) Gerenciar as despesas pessoais do proprietário e de sua família e 3) Medir e avaliar o desempenho econômico-financeiro da empresa por atividade. Complementando a análise, é possível verificar que esta visão de maior foco prestação de contas ao governo ou físco (como apontado entre as principais finalidades das anotações), é convergente com os achados em pesquisas internacionais, onde os produtores entendem a contabilidade útil principalmente para as obrigações fiscais (ARGILÉS; GARCIA-BLANDON; MONLLAU, 2011; BOSCH; ALIBERCH; GARCIA-BLANDÓN, 2012).

Nesta investigação, verificou-se que os agricultores na sua maioria fazem um planejamento no início de cada safra, enquanto no trabalho Salume, Silva e Christo (2015) os agricultores não o fazem. E que em ambas há investimentos na atividade com os lucros obtidos.

\section{CONSIDERAÇÕES FINAIS}

A partir dos dados coletados pode-se verificar que, os agricultores sabem da importância da contabilidade, mas, não são todos que a utilizam em seu dia a dia. De certa forma, existe o controle dos custos por meio de anotações simples, as quais dão suporte quando precisam tomar alguma decisão, ressaltando que estas anotações não são 100\% do que acontece, buscam anotar, controlar as despesas/custos que possuem valores relevantes. Destaca-se que apenas 8 dos 27 respondentes $(30 \%)$ que fazem anotações utilizam-se destas informações como apoio para a tomada de decisão, o que demonstra que ainda há espaço para desenvolvimento desta competência na área.

É por meio dessas anotações que conseguem definir o custo aproximado que incorrem na safra, tendo assim por base o tamanho de seu investimento, de forma a conseguir ver se ao final o valor recebido pelo o que foi produzido é suficiente para cobrir todos os custos.

A falta dessa contabilidade pode se dar por causa da não obrigatoriedade de escrituração contábil, a única obrigação é referente ao imposto de renda, que esses agricultores pessoas físicas estão obrigados a apresentar.

Verifica-se também que grande parte dos entrevistados conhece a importância de separar os gastos pessoais com o da atividade, não ferindo assim o pressuposto da entidade. Vale ressaltar que $53 \%$ dos entrevistados sabem que a função da contabilidade principal para eles é o auxílio no seu controle de custos e tomada de decisão, que possibilita trazer dados confiáveis no momento em que precisarem, no entanto, apenas $20 \%$ estão com a contabilidade em dia, sendo que a maioria atenta-se mais a esta na época de declarações fiscais (imposto de renda).

Os achados demonstram que apesar da evolução tecnológica no campo, o avanço nos modelos de financiamento e desenvolvimento do agronegócio, os controles contábeis da atividade ainda são considerados básicos. Os dados demonstram que em grande parte os controles existentes são para fins fiscais, com reduzido uso decisorial. Esta subutilização da contabilidade pode deixar de contribuir para a evolução patrimonial do produtor rural, uma vez que possíveis ineficiências no processo produtivo podem estar passando de forma despercebida pela ausência de um controle mais rigoroso nos custos de produção.

Este cenário, no entanto, não diverge do encontrado em outras pesquisas nacionais e internacionais (FAVATO; NOGUEIRA, 2017; ARGILÉS; GARCIA-BLANDON; MONLLAU, 2011; BOSCH; ALIBERCH; GARCIA-BLANDÓN, 2012), o que pode sugerir que talvez seja importante para os órgãos governamentais, associações de produtores rurais, 
cooperativas etc. pensarem sobre a disponibilização de cursos de formação (ou consultores financeiros) para controle dos custos de produção e planejamento financeiro familiar, visando contribuir com a gestão financeira do produtor.

No período pós-crise de 1929, nos Estados Unidos, Walker (2014) destaca a iniciativa do governo de oferecer apoio para a reabilitação dos produtores rurais. Além de empréstimos, o governo ofereceu também apoio de um supervisor na gerência financeira, tanto de produção quanto familiar. Os resultados indicam que este uso da contabilidade e do supervisor auxiliando no controle de custos dos produtores promoveu redução da pobreza (grande parte gerada pela crise de 1929) e maior controle patrimonial, sendo que era elaborado um modelo básico de balanço patrimonial (com ativos e passivos) dos produtores rurais, além de outros controles.

Os resultados desta pesquisa devem ser observados considerando as seguintes limitações: a pesquisa foi realizada em uma única cidade em determinado período; foram analisados apenas os agricultores que se teve acesso, assim, não é possível generalizar as conclusões para a população.

Sugere-se que futuras pesquisas investiguem sobre outras regiões do Brasil, ou que até mesmo faça comparativos com outras pesquisas já executadas, comparando assim as igualdades e desigualdades no pensar de cada agricultor em diferente região do Brasil. Além disso, pesquisas que façam experimentos ou acompanhem produtores rurais por períodos mais longos podem contribuir de forma significativa com a literatura, evidenciando se determinados cursos ou acompanhamentos financeiros surtiram efeitos positivos (ou negativos) na gestão da propriedade.

\section{REFERÊNCIAS}

ANDRADE, M. G. F.; MORAIS, M. I.; MUNHÃO, E. E.; PIMENTA, P. R. Controle de custos na agricultura: um estudo sobre a rentabilidade na cultura da soja. Custos e Agronegócio Online, Recife, v. 8, n. 3, p. 24-45, 2012.

ARGILÉS, J. M.; GARCIA-BLANDON, J.; MONLLAU, T. Fair value versus historical costbased valuation for biological assets: Predictability of financial information. Revista de Contabilidad-Spanish Accounting Review, v. 14, n. 2, p. 87-113, 2011.

BOSCH, J. M. A.; ALIBERCH, A. S.; GARCIA-BLANDÓN, J. A comparative study of difficulties in accounting preparation and judgement in agriculture using fair value and historical cost for biological assets valuation. Revista de Contabilidad, v. 15, n. 1, p. 109-142, 2012.

BRASIL. Lei $\mathrm{n}^{\circ}$ 8.629, de 25 de fevereiro de 1.993. Regulamentação dos dispositivos constitucionais relativos à reforma agrária. Diário Oficial da República Federativa do Brasil, Brasília, DF, 25 fev. 1.993.

BRAUM, L. M. S.; MARTINI, O. J.; BRAUN, R. S. Gerenciamento de custos nas propriedades rurais: uma pesquisa sobre o uso dos conceitos da contabilidade de custos pelos produtores. In: CONGRESSO BRASILEIRO DE CUSTOS, XX, 2013, Uberlândia. Anais [...]. Uberlândia: ABCustos, 2013, p. 1-16.

BRIGHENTI, J.; ZANIN, A.; OENNING, V.; KRUGER, S. D. Aspectos da mensuração contábil na avicultura no sistema de parceria. In: Seminário Integrado: Ensino, Pesquisa e Extensão, III, 2011, Chapecó. Anais [...]. Chapecó: Unochapecó, 2011, p. 1-15. Disponível em: 
<https://www.unochapeco.edu.br/seminariointegradoepe/downloads/aspectos-da-mensura-ocont-bil-na-avicultura-no-sistema-de-parceria/down>. Acesso em 20 de agosto de 2016.

CALlADO, A. A. C.; CALLADO, A. L. C. Custos na tomada de decisões em empresas rurais. In: CONGRESSO BRASILEIRO DE CUSTOS, V, 1998, Fortaleza - CE. Anais [...]. Fortaleza: ABCustos, 1998, p. 1-17.

CREPALDI, S. A. Contabilidade gerencial: teoria e prática. 4. ed. São Paulo: Ed. Atlas, 2008.

Contabilidade rural: uma abordagem decisorial. 7. ed. São Paulo: Ed. Atlas, 2012.

FAVATO, K. J.; NOGUEIRA, D. R. Produtor rural familiar: um estudo sobre a adesão aos controles de custos na cidade de Londrina-PR. Extensão Rural, v. 24, n. 4, p. 102-117, 2017.

GIL, A. C. Métodos e técnicas de pesquisa social. 6. ed. São Paulo: Atlas, 2008.

HANSEN, D. R., MOWEN, M. M. Gestão de custos contabilidade e controle. São Paulo: Pioneira Thomson Learning, 2001.

HOFER, E.; RAUBER, A. J.; DIESEL, A.; WAGNER, M. Gestão de Custos Aplicada ao Agronegócio: culturas temporárias. Contabilidade Vista \& Revista, Belo Horizonte, v. 17, n. 1, p. 29-46, 2006.

Instituto Ambiental do Paraná (IAP). Módulos Fiscais dos Municípios do Estado do Paraná. Disponível em: <http://www.iap.pr.gov.br/>. Acesso em: 29 de janeiro de 2017.

KRUGER, S. D.; GLUSTAK, E.; MAZZIONI, S.; ZANIN, A. A Contabilidade como Instrumento de Gestão dos Estabelecimentos Rurais. REUNIR: Revista de Administração, Contabilidade e Sustentabilidade, v. 4, n. 2, p. 134-153, 2014.

KRUGER, S. D.; MAZZIONI, S.; BOETTCHER, S. F. A importância da contabilidade para a gestão das propriedades rurais. In: Congresso Brasileiro de Custos, XVI, 2009, Fortaleza. Anais [...]. Fortaleza: ABCustos, 2009, p. 1-10.

LEONE, G. S. G.; LEONE, R. J. G. Curso de contabilidade de custos. 4. ed. São Paulo: Ed. Atlas, 2010.

MARTINS, Eliseu. Contabilidade de custos. 9. ed. São Paulo: Ed. Atlas, 2003.

SALUME, J. A.; SILVA, E. C. G.; CHRISTO, B. F. Elementos de administração rural avaliados em pequenas propriedades rurais de Alegre - ES. Caderno Profissional de Administração UNIMEP, Piracicaba, v. 5, n. 1, p. 76-93, 2015.

SANTOS, G. J.; MARION, J. C.; SEGATTI, S. Administração de custos na agropecuária. 3. ed. São Paulo: Ed. Atlas, 2008.

SEVERO, P. S.; TINOCO, J. E. P.; OTT, E. Contabilidade de pequeno produtor rural de alimentos: utilização da metodologia Balanço Perguntado. Custos e Agronegócio online, v. 
13, n. 2, p. 45-72, 2017.

SILVA, R. C.; LOPES, A. C. V. Análise de custo da produção do milho safrinha: um estudo numa pequena propriedade. In: CONGRESSO DA SOCIEDADE BRASILEIRA DE ECONOMIA, ADMINISTRAÇÃO E SOCIOLOGIA RURAL, XLVI, 2008, Rio Branco-AC. Anais [...]. Rio Branco: SOBER, 2008, p. 1-14. Disponível em: <http://ageconsearch.umn.edu/handle/102553>. Acesso em: 20 de agosto de 2016.

WALKER, S. P. Accounting and rural rehabilitation in New Deal America. Accounting, Organizations and Society, v. 39, n. 3, p. 208-235, 2014.

ZANIN, A.; OENNING, V.; TRES, N.; KRUGER, S. D.; GUBIANI, C. A. Gestão das propriedades rurais do Oeste de Santa Catarina: as fragilidades da estrutura organizacional e a necessidade do uso de controles contábeis. Revista Catarinense da Ciência Contábil - CRCSC, Florianópolis, v. 13, n. 40, p. 9-19, setembro/dezembro, 2014. 